\title{
22 Intuition: Scientific, Non-Scientific or Unscientific?
}

\author{
Viktor Dörfler and Alina Bas
}

\begin{abstract}
In this chapter we propose expanding the scope of what is covered by scholarly research on intuition. Specifically, we suggest expanding this research into an area often labeled as unscientific. Much of what is considered scientific knowledge today used to be outside the realm of scientific, until someone achieved an understanding of a phenomenon that enabled scientific inquiry. Based on this premise, we argue that what is not scientifically understood about intuition is not unscientific, but non-scientific. We put forward a model of the process of intuiting, which demystifies a part of the phenomenon previously dismissed by scholars, enabling further research.
\end{abstract}

Keywords: intuition, sensing, sensemaking

\section{INTRODUCTION}

There has been a recent rejuvenation of interest in the phenomenon of intuition in the scholarly research, especially in the area of psychology, as well as in management and organization scholarship. This research interest was increasingly intensified over the past 15 years, resulting in a large number of academic papers on intuition. As part of this development, the scope of what is included in the academic research became a contested topic of conversation. Besides minor disagreement among researchers, we have found bigger gaps in understanding between some practitioners and academics who study intuition. In order to identify and explore these gaps, we introduce the concept of intuition practitioners as those who intentionally use intuition in their practice, even when the scientific underpinnings of it are missing or not fully understood, and intuition scholars as those who conduct academic research on the topic of 
intuition using some form of a scientific method. We believe it is important for intuition scholars to not leave out something significant by labeling the 'not yet understood' as 'unscientific'. Therefore, in this book chapter we propose an extension of the scope of intuition research by shedding light on the process of intuiting (the outcome of which is intuition), utilized by intuition practitioners and not yet understood by intuition scholars.

We craft our argument without being dismissive of the scientific approach, and also without dismissing ideas that currently do not fit into what is scientifically accepted. We illustrate the fruitfulness of this extension by proposing a new two-stage model of intuiting. It is important to note that the idea for this model originated as a result of a discrepancy between the way intuition scholars and intuition practitioners describe intuiting. Intuition practitioners' claims are frequently dismissed by academics, but it does not mean that intuition practitioners' views are unfounded. Our model provides foundation for claims by intuition practitioners, while at the same time, accounting for the observations made by intuition scholars.

We first describe some of least contested dimensions of intuition. Then, in order to understand the disagreement between intuition scholars and intuition practitioners, we outline the dynamics between the scientific, non-scientific, and unscientific knowledge, taking a historical perspective on the interplay between the three. To this end, we introduce the notion of 'three knowledge buckets'. Using the three buckets, we show the way for bringing under scientific scrutiny, without compromising the scientific rigor, aspects of intuiting that were previously dismissed. Subsequently we outline the current understanding of intuiting by intuition scholars and then by intuition practitioners, pointing out the gap between the two perspectives. We attempt to explain the gap by proposing a two-stage model of intuiting: sensing + sensemaking. Finally, in our commentary, we demonstrate that the proposed twostage model of intuiting is compatible with the current academic understanding of intuition, and enriches it by providing additional depth. Our aim for this chapter is to reconcile intuition 
scholars' and intuition practitioners' views of intuiting, and offer a sensing + sensemaking model for consideration, conceptual criticism and empirical testing by other scholars.

\section{WHAT IS INTUITION?}

Until about 30 years ago, intuition as a whole was poorly understood as a concept, poorly defined, and as a result, under-studied (Akinci \& Sadler-Smith, 2012). Gradually, as the scholarly understanding of intuition started to emerge, several aspects of intuition were brought into the scientific realm. This includes explaining intuiting in terms of dual processes (e.g. Epstein et al., 1996; Hodgkinson et al., 2008; Kahneman \& Frederick, 2002; Neisser, 1963; Stanovich \& West, 1998; Tversky \& Kahneman, 1983), expertise (e.g. Dörfler \& Stierand, 2017; Hogarth, 2001; Kahneman \& Klein, 2009; Prietula \& Simon, 1989; Salas et al., 2010), as well as heuristics and biases (e.g. Kahneman, 2003; Kahneman et al., 1982; Tversky \& Kahneman, 1974). There are still ongoing debates about whether it is meaningful or useful to classify intuition by types, i.e. expert intuition (Kahneman \& Klein, 2009), strategic intuition (Duggan, 2013), entrepreneurial intuition (Kickul \& Gundry, 2011), etc.

Intuiting can be conceptualized as a way of 'direct knowing', that is, knowing "without any use of conscious reasoning" (Sinclair \& Ashkanasy, 2005: 357). Although this is certainly not a precise definition, it is generally accepted in the intuition scholarship. Direct knowing means that knowledge is not achieved by the step-by-step reasoning, which typically characterizes the academic view of knowing, but through a process that somehow seems to bypass these steps.

The beginning of the renewed interest in intuition in management and organization studies was marked by Chester Barnard's (1938) seminal book 'The Functions of the Executive'. Although Chester Barnard was a practitioner, his book has been widely accepted in the academia. The first academic inquiry to account for intuiting was Herbert Simon's work on 'Administrative Behavior' (first edition published 1947). It led to one of the most cited maxims 
on intuition: "Intuition and judgment - at least good judgment - are simply analyses frozen into habit" (Simon, 1987: 63). This was followed by the first empirical study by Weston Agor (1986), in which he explored both successes and failures of intuition. This book is halfway between academic and practitioner publications. Currently, some major characteristics of intuiting have been generally accepted by both scholars and practitioners; these characteristics will be discussed below in detail. As we review these characteristics, we point out one significant disagreement between intuition scholars and intuition practitioners: whether intuition can be intentional as well as spontaneous. The concept of the three knowledge buckets, and the movements of knowledge between them, will help expand our understanding of intuition and intuiting.

\section{THE THREE KNOWLEDGE BUCKETS}

We suggest that any knowledge, whether obtained through practice, academic research, or by any other means, fits into one of the three metaphorical buckets: scientific, non-scientific, and unscientific. Scientific knowledge is accepted as true in science based on scientific evidence obtained through a scientific method. Unscientific is rejected as false by science based on scientific evidence obtained through scientific method. Non-scientific is currently not covered by science; it is neither accepted nor rejected based on scientific evidence.

Before any scientific inquiry has been made about a particular phenomenon, the pre-existing explanation is always in the non-scientific bucket. When a scientific study is undertaken, one of the four things can happen:

1. If the scientific inquiry supports the pre-existing explanation, thus legitimizing it as a scientific explanation, this explanation is placed in the scientific bucket.

2. If the pre-existing explanation is dismissed (conclusively proven false) by the scientific inquiry, it is transferred into the unscientific bucket. Dismissing the pre-existing 
explanation as unscientific may go together with obtaining a new scientific explanation that is incompatible with the pre-existing explanation, this new explanation will then be put into the scientific bucket.

3. If the scientific inquiry neither proves nor falsifies the pre-existing explanation of the phenomenon, it will remain in the non-scientific bucket.

4. Finally, there may be cases, where a new scientific explanation is obtained, and placed in the scientific bucket, while the pre-existing explanation will remain in the nonscientific bucket, as the scientific explanation neither contradicts nor supports it. Thus, the two explanations can continue to coexist.

Everything science has proven wrong eventually moves from the non-scientific to the unscientific bucket, and everything, for which science has sufficient supporting evidence, moves from the non-scientific to the scientific bucket. However, there will always be knowledge remaining in the non-scientific bucket, containing whatever science did not prove (yet) to be right or wrong. Unfortunately, those who worship science, have a tendency to treat the non-scientific bucket in the same manner as the unscientific one, dismissing its content as wrong, without well-founded evidence. Even though it may not always be possible to differentiate immediately in which knowledge bucket a particular explanation (or part of an explanation) belongs, this should not lead to a premature assumption that the explanation is unscientific. Intuition is one such phenomenon: it has parts of explanations in the scientific and some in the non-scientific knowledge buckets.

We believe we have found something on intuiting in the non-scientific bucket deserving a closer look through a scientific prism. It is an explanation of intuiting provided by intuition practitioners, which focuses on the sensory aspects of intuition. This non-scientific explanation can potentially be transferred from non-scientific into scientific, as it passes scientific scrutiny. 
While it may be easy to dismiss intuition practitioners' explanation as unscientific, we insist it is essential to prevent moving ideas into the unscientific from the non-scientific bucket without examination.

The academic explanation of intuiting is an amalgamated body of knowledge grounded in and supported by systematically gathered, and tested evidence. In contrast, the practice-based explanation focuses on the individual experiences, and relies on a fragmented body of knowledge, un-systematized terminology, and anecdotal rather than systematic evidence. Until about 25 years ago, nearly all knowledge about intuiting belonged in the non-scientific bucket (and was often dismissed as unscientific by the academic community at large). Gradually, the scientific understanding of intuiting began to emerge. As a result, some aspects of intuiting are currently in the scientific bucket, as they already have scientific explanations, while other aspects of intuiting are in the non-scientific bucket, with practice-based explanations.

Our comprehensive model conceptualizes the intuitive process as sensing + sensemaking, and creates a pathway for moving more aspects of intuiting from the non-scientific to the scientific bucket through scientific exploration, and without giving up the understanding obtained through the practice-based explanations. Intuition practitioners understand intuiting through their senses rather than explanations, while intuition scholars understand intuiting through explanations rather than sensing; the two types of understanding do not contradict each other.

\section{WHAT INTUITION SCHOLARS KNOW}

The literature on intuiting within the management and organization scholarship identified six necessary and sufficient characteristics that define intuiting (cf Dane \& Pratt, 2007; Dörfler \& Ackermann, 2012; Dörfler \& Stierand, 2017; Kahneman, 2003: 698; Sadler-Smith, 2008: 13; Sinclair, 2010): 
- Intuiting is rapid, meaning that it occurs almost instantaneously, and in this respect, it is similar to guessing. However, it is guessing which is "frequently correct" (in line with Simon, 1983: 25).

- Intuiting is alogical, meaning that it operates independently of the general principles of reasoning that we call logic, therefore it is neither logical nor illogical, as it neither follows nor contradicts the rules of logic.

- Intuiting is holistic or gestalt, as it is about the 'big picture' of the situation, including the broad context, and far reaching implications. It even takes into account what we could call 'invisible parts' inaccessible to deliberate step-by-step reasoning, sometimes referred to as the 'unknown unknowns'. Furthermore, intuiting also involves the totality of the intuitor.

- Intuiting is tacit in the sense that intuitors can describe the outcome, but not the way they arrived at it. Although intuitors are often good at defending their intuitive judgments or insights, there is no evidence that the justification has anything to do with the way the intuiting was used.

- Intuition, as the outcome of intuiting, has an intrinsic certainty: intuitors are confident they have the right answer. This does not make intuiting infallible, and intuitors do not usually claim infallibility. We will revisit what is known about the reliability of intuiting below.

- Finally, intuiting is considered to be spontaneous. This means that intuiting does not require conscious effort, at least at the moment when it happens. This is the one feature where intuition scholars and intuition practitioners are in disagreement.

These features are grounded in empirical research - predominantly interviews with practitioners, including decision takers and creative problem solvers. 
Besides the above-mentioned six features of intuiting, it is also often mentioned that intuiting is frequently accompanied by somatic (visceral) effects and affective charges. While the role of affect in intuiting and intuition has been addressed (e.g. Coget, 2011; Dane \& Pratt, 2007; Sinclair, 2010), the somatic apsects are much less understood (e.g. Tantia, 2011, 2014). Although presence of affect in the intuitive process and outcome does not contradict any of the findings in intuition research, it still lacks solid foundation, and empirical support. Affective and somatic aspects of intuiting are mentioned cautiously by intuition scholars, since these two aspects are not yet solidly in the scientific bucket, but they can be pertinent in terms of relating to the intuition practitioners' view of intuition.

It is important to note that the scholarly discourse on intuiting is tightly linked with the notion of expertise. Domain expertise is not limited to disciplinary expertise; it can be expertise in a particular problem area which is transdisciplinary. With this broad view of expertise, it can be argued that nearly all scholarly knowledge on intuiting either refers to experts' intuiting or is based on it. A closer look at studies claiming to have provided experimental evidence on the failure of intuiting (including Bowers et al., 1990: 97; Schoemaker \& Russo, 1993: 27; Trailer \& Morgan, 2004) reveals that these experiments targeted novice intuition. In contrast, those (including Burke \& Miller, 1999 in management; Hayashi, 2001 in leadership; Keren, 1987 in the game of bridge) who have found empirical (predominantly non-experimental) evidence of intuiting working well typically focused on intuiting of people at high level of domain expertise (Dane et al., 2012; Mielonen et al., 2009). Dane et al. (2012) conducted two comparative experiments, which confirmed the importance of expertise in reliability of intuiting. Kahneman and Klein (2009) concluded the same in their conceptual discourse grounded in years of research on intuition. Expert intuition is the best understood phenomenon within intuition research, although this does not imply that it is fully understood. Interestingly, once people become experts in their respective domains, intuiting becomes their predominant way of 
thinking in their domains (Dörfler \& Ackermann, 2012; Kahneman \& Klein, 2009). Expertise aids "fast thinking" (Kahneman, 2011) by enabling rapid pattern recognition (Chase \& Simon, 1973), and recognition-primed decision-making (Klein, 2015).

There is still a great deal of knowledge about intuiting in the non-scientific bucket. Unfortunately, academic hubris can push to dismiss everything about a particular phenomenon in the non-scientific bucket as unscientific, once there is substantial knowledge accumulated in the scientific bucket. The claim is that if there was any evidence supporting scientific foundation of something in the non-scientific bucket, it would have already come into the light, which lacks basis. It is therefore useful to look from time to time at what practitioners do in the same area as scholars: if something seems to work in practice, but did not make its way into the scientific bucket yet, it is worth exploring. This is why we now focus on the way intuition practitioners see intuiting.

\section{WHAT INTUITION PRACTITIONERS KNOW}

Practice-based explanation of intuiting is founded on accounts of intuition practitioners, who consistently use intuiting, intentionally, on cue. Intuition practitioners do not describe intuiting as scientific, non-scientific or unscientific. Instead, they explain intuiting as practical: they claim to have tacit or explicit understanding of the way intuiting works, use it intentionally, and even help others become more attuned to their intuiting (Day, 1997). Their understanding of intuiting is typically rejected within the realm of science, because it is not based on evidence acquired through a scientific method. Still, it does not prevent practitioners from using their intuiting.

Furthermore, intuition practitioners see intuiting as a sensory-based, direct way of obtaining awareness of phenomena, which is in line with what is usually viewed as lacking scientific foundation. There are numerous reasons why this makes some scientists uncomfortable: some 
scoff at the subjectivist approach to knowing, others object to lack of scientific method for exploring the sensory-based phenomena, while others are simply oblivious to the sensing aspect of intuiting. Interestingly, affect and visceral sensations in intuiting, which are somewhat marginalized by intuition scholars, are essential to intuition practitioners: affective and visceral cues typically serve as starting points that make intuition practitioners pay attention to intuiting (Bas, 2013). Intuition practitioners employ a sensory-based way of obtaining awareness of phenomena, achieving first-hand experience. By 'sensory' we imply perception based on the five primary senses, as well as visceral (e.g. hunger), affective (e.g. love), and mental sensations (e.g. pride) (Burton, 2009: 37). It is a way of coming to know something, without necessarily knowing how this knowledge was obtained.

While intuition practitioners may or may not describe intuiting as rapid, tacit, holistic, alogical, and having intrinsic certainty, as scholars do, they often talk about intuition as both spontaneous and intentional (Day, 1997). In contrast to the academic literature, which provides ample examples of intuition occurring to people spontaneously (Dane \& Pratt, 2007; SadlerSmith, 2008), there has been recent additional evidence from practitioners, suggesting that intuiting can also be produced on cue (Beck, 2011: 137; Day, 1997: 23; 2009: 41; Mielonen et al., 2009). For example, intuitive flashes could be conjured up by asking oneself a question about a situation, or defining a desired outcome, and staying attuned with soft focus to sensory and environmental cues emerging in response to the initial inquiry (Day, 1997, 2009). After posing a question, intuition practitioners may listen and look for shifts in the mental, physical and affective states (see also 'passionate intention' in Bradley, 2011: 210; and 'indwelling' in Dörfler \& Stierand, 2018). These shifts seem to occur without apparent causes either from the external environment or from internal processes, and hence labeled as intuitive.

Intentionality of intuiting is currently often dismissed by scholars as unscientific, without examination, as it is so poorly understood. An intuition practitioner may explain intentionality 
in intuiting much like developing musicality while learning to play a musical instrument (Bas, 2013: 9). At first, a music student must learn all the notes by name, as well as the practical mechanics of the instrument. The first equivalent step in intuiting would be an attempt to notice and differentiate between sensory experiences. After learning the names and graphic representations of the notes, a student would learn to hear the difference between the notes, and feel the difference between the notes in the fingers, much like intuition practitioners would learn to sense individual 'notes' in their range of physical, emotional, and mental perception. After plentiful practice of corresponding the written notes to the touched keys, and the heard sounds, gifted and well-trained students would be able to play what is seen on a page, and to play what is heard by the ear, as well as to hear in their mind's ear the music written on the paper. Similarly, a trained intuition practitioner can decipher sensory-based cues, and translate them into meaningful and useful information beyond the actual sensation.

An analytical thinker, not experienced in paying attention to sensing, may wonder how it is possible to get intuitive information seemingly out of nowhere, unless one is able to justify it as expertise. For intuition practitioners, however, expertise is much less tied to intuiting than the scholarly literature implies. Intuition practitioners suggest that over time, a student of intuiting could learn to understand various sensations underpinning their intuiting, such as the colors, words, images, tastes, textures, and intentionally making sense of these sensations can create a useful, actionable narrative. To the musically challenged, observing someone differentiate between F\# and G in the third octave just by hearing the sounds may sound like a lucky guess or a sort of a magic trick. Similarly, when it comes to intuiting, it may seem just as mysterious to observe someone differentiate among the meanings of other sensory signals (Bas, 2013). A person who is not particularly musical or musically trained will not be able to tell with certainty whether F\# and G are different sounds or the same sound, unless the sounds are played back to back without interference or delay between them. To a highly trained 
musicians, even the notion of confusing F\# and G may seem strange, because they perceive the two notes as two distinct sounds. A trained intuition practitioner is similarly able to distinguish between, for example, an intuitive signal and hope.

Intuition practitioners rarely argue with scholars' explanations of intuiting. In our view, this increases credibility of the explanations of intuiting in the scientific bucket. However, a discrepancy between something that works in practice, but cannot be accounted for by the knowledge in scientific bucket is alerting. It implies that either intuition scholars made a mistake (e.g. lack of rigor in applying the chosen scientific method or unjustified claim of validity), or simply did not cover all the bases yet. We will now try to unpack one such discrepancy.

\section{WHY INTUITION SCHOLARS AND INTUITION PRACTITIONERS SEE}

\section{DIFFERENTLY}

Intuition scholars accept only the aspects of intuiting that can be scientifically explained. If they dismiss everything else, they will only see what is in the scientific bucket. Intuition practitioners accept all aspects of intuition that work. This means that intuition practitioners see both the scientific and the non-scientific buckets. Practitioners may or may not be aware of the intuiting features described by intuition scholars. They may have a feeling or may know from reading that intuiting is rapid, alogical, holistic, tacit, has intrinsic validity, and is often spontaneous, but they do not necessarily think about it or are able to articulate it. They would not argue with the scientific view, and would add that intuiting can be intentional as well as spontaneous.

The main difference between the views of intuition practitioners and intuition scholars is in the way they think about sensory inputs. Intuition practitioners aim at attaining insight into hidden truths through immersing themselves in a phenomenon, thus the focus is on the personal 
(individual) experience. This means taking the subjectivity to the extreme in order to reach understanding. In contrast, intuition scholars, at least traditionally, aim at attaining insight into hidden truths by getting rid of everything personal and subjective, and penetrating the phenomenon in an impersonal objective way. As Schrödinger (1958) argues in his discourse on the so called 'scientific method', science is also ultimately sensory-based: even if we design a machine that designs another machine that does the measurement and the processing in itself, there is still a starting point somewhere, where the initial machine was designed by a human using sensory-based approach. Similarly, there is also always a human interpretation of the outcome at the end of whatever data the machines collected and processed, which is why Gummesson (2003) claims that all research is interpretive.

Intuition practitioners' and intuition scholars' views of intuiting bring to mind a famous Indian parable about the blind men and an elephant. As each of the blind men was touching a different part of an elephant, they described their experiences very differently, making it seem as if they were interacting with entirely different entities. Intuition practitioners and intuition scholars have different purposes for, and different roles in, understanding intuiting, which may make it seem like they are looking at different phenomena. As we will demonstrate below, this may not be the case. Perhaps intuition practitioners' views can inform and enable the scientific inquiry, and we can reconcile the difference between the two modes of knowing.

\section{COMPREHENSIVE VIEW OF INTUITING: SENSING + SENSEMAKING}

In this section we bring together the intuition scholars' and the intuition practitioners' views of intuiting, covering both the scientific and the non-scientific buckets. If we were only practitioners, we would not need to do this, because, as we stated above, intuition practitioners can see both scientific and non-scientific. However, we make an attempt to synthesize the views as scholars, thereby extending the scope of the scientific bucket by providing 
scientifically acceptable explanation of aspects of intuiting currently in the non-scientific bucket.

Both intuition scholars and intuition practitioners acknowledge that some interpretation takes place as a part of the intuiting process. We call this the sensemaking aspect of intuiting. This sensemaking can be described by five of the six characteristics identified by intuition scholars: it is rapid, holistic, alogical, based on tacit processing, and carries intrinsic certainty. We have identified one characteristic on which intuition scholars and intuition practitioners disagree when describing the way intuiting works: intentionality. Intuition practitioners' explanation allows for a possibility that the intuiting process can be initiated on cue, while the scholarly explanation claims that intuition is spontaneous, not allowing for intentionality.

This discrepancy may be explained by the fact that the scholarly view disregards the sensory aspect of intuiting, while for intuition practitioners, intuiting is rooted in the sensory, and it is in the sensory realm where intentionality of intuiting process can be achieved. Although intuition as an outcome is naturally spontaneous, the process of intuiting may or may not be spontaneous; it is plausible that practice-based and scholarly explanations address different phases of the intuiting process.

Looking at the process of intuiting, the product of which is intuition, we divide the process of intuiting into sensing and sensemaking. It can then potentially be understood what each phase entails, and how one's ability to capitalize on each phase can be improved. The model allows for both practitioner and scholarly claims about spontaneity versus intentionality of intuiting to be possible at the same time. On the input side of sensing, there are sensory signals, which in the process of sensing are transformed into sensations. These sensations, tacit or explicit, are the inputs of the sensemaking process, the output of which is meaning. Thus the process of intuiting, described as 'sensing + sensemaking', produces 'sensations with 
meaning', that is, intuition. While not all 'sensation with meaning' is intuition, all intuition is 'sensation with meaning'.

The sensing aspect of intuiting entails perceived signals. One example is a visual image either in a mind's eye or in a tangible world, which suddenly catches a person's attention. Other examples include auditory sensations (again, either in a mind's ear, or also potentially observable to others), tactile sensations, or changes in one's physical and emotional state (Mielonen et al., 2009). Intuiting presents to each person in a sensory language, which is unique to him or her due to physiological and psychological differences, and therefore it cannot be standardized. For instance, the same visual image can represent different ideas to different people, or even to the same person in different contexts. Hence, sensing must be followed by sensemaking in order for sensing to acquire additional meaning, and thus become usable.

Sensemaking (Weick, 1979, 1995) is the aspect of intuiting concerned with revealing the meaning of signals perceived through sensing, and appears to be tied to one's domain expertise, relevant to the particular situation. One may not be aware of the sensing part at all, as one only perceives the signals of which one has already made sense. It may seem unclear, vague, and unexplainable to scholars what happens (or whether anything happens) during the sensing stage. This dismissal, or lack of understanding, keeps the sensing part of intuiting in the category of non-scientific. In this light, it is understandable why scholars may not distinguish between 'the outcome of intuiting', which is intuition, and 'the output of sensemaking', which is meaning. This also explains why intuiting is tightly linked with domain expertise in the scholarly view: domain experts are competent at interpreting all sorts of inputs within their area of expertise. Ignoring the sensing aspect of intuiting makes concept of intuiting incomplete. 


\section{COMMENTARY}

By offering the sensing + sensemaking model of intuiting, we open up new avenues of research on intuiting, for which this model can serve as a conceptual framework. Furthermore, the model, which can be useful for people who are interested in making better use of their intuition, bridges the practical and the scholarly view. It enables training the sensing aspect of intuiting without leaving the realm of the scientific mindset.

Sensing in the process of intuiting is equivalent to perceiving and differentiating among sounds in the process of becoming a musician. It requires practice in learning to sense the difference, and getting accurate feedback during practice (Ericsson \& Pool, 2016: 17). Sensemaking in the process of intuiting is equivalent to knowing what each note represents on an instrument, and making decisions as a result of having this knowledge.

Based on this model, it is possible to get more specific about educating intuiting. The sensing phase of intuiting can be improved through developing physical, emotional, and intellectual self-awareness, while the sensemaking phase can be educated through increasing domain expertise or context expertise (Dörfler \& Stierand, 2017; Sinclair, 2010; Sinclair et al., 2002). The Western educational system is fully focused on the latter, while the sensing is systematically repressed (Bergson, 1911; Hogarth, 2001). Top professionals in any area of expertise - be it musicians, chefs, athletes, designers, or scientists - are esteemed precisely for their 'sense of the game' in their domains, even when formally they are recognized for expertise (Bruner, 1977: 67), so sensing is worth developing along with sensemaking in order to achieve highest levels of performance.

There is nothing in the intuition practitioners' view of intuiting that contradicts scientific evidence. The disagreement we have identified is between opinions of intuition practitioners, and scholars. The scholarly opinion is informed by the scientifically obtained evidence that 
intuition can manifest spontaneously. However, this does not mean that 'spontaneous' is the only way in which intuiting can manifest. There is no scientific evidence that contradicts the claim of the intuition practitioners' view that intuiting can be originated intentionally, as well as spontaneously. This means that intuition practitioners' claim of possible intentionality of intuiting belongs in the non-scientific bucket, rather than in the unscientific one, and with further research, it has potential to move to the scientific bucket, provided that the sensing + sensemaking model of intuiting sustains scientific scrutiny.

\section{REFERENCES}

Agor, W. H. 1986. The logic of intuition: How top executives make important decisions. Organizational Dynamics, 14(3): 5-18.

Akinci, C. \& Sadler-Smith, E. 2012. Intuition in management research: A historical review. International Journal of Management Reviews, 14(1): 104-122.

Barnard, C. I. 1938. The functions of the executive. Cambridge, MA: Harvard University Press.

Bas, A. 2013. Skeptic's guide to intuition: How developing intuition can improve the way you live and work (Kindle edition ed.): The Difference Press.

Beck, M. 2011. Finding your way in a wild new world: Reclaim your true nature to create the life you want. New York, NY: Simon and Schuster.

Bergson, H. 1911. Creative evolution. New York, NY: Henry Holt and Company.

Bowers, K. S., Regehr, G., Balthazard, C., \& Parker, K. 1990. Intuition in the context of discovery. Cognitive Psychology, 22(1): 72-110.

Bradley, R. T. 2011. Resolving the enigma of nonlocal intuition: A quantum-holographic approach. In M. Sinclair (Ed.), Handbook of intuition research: 197-213. Cheltenham, UK: Edward Elgar Publishing. 
Bruner, J. S. 1977. The process of education ( $2^{\text {nd }}$ ed.). Cambridge, MA: Harvard University Press.

Burke, L. A. \& Miller, M. K. 1999. Taking the mystery out of intuitive decision making. Academy of Management Executive, 13(4): 91-99.

Burton, R. A. 2009. On being certain: Believing you are right even when you're not. New York, NY: St. Martin's Press.

Chase, W. G. \& Simon, H. A. 1973. Cognitive Psychology., 4(1): 55-81.

Coget, J. 2011. The critical decisions vortex-interplay of intuition, reason and emotion: Comparison of three dynamic industries. In M. Sinclair (Ed.), Handbook of intuition research: 133-144. Cheltenham, UK: Edward Elgar.

Dane, E. \& Pratt, M. G. 2007. Exploring intuition and its role in managerial decision making. Academy of Management Review, 32(1): 33-54.

Dane, E., Rockmann, K. W., \& Pratt, M. G. 2012. When should i trust my gut? Linking domain expertise to intuitive decision-making effectiveness. Organizational Behavior and Human Decision Processes, 119(2): 187-194.

Day, L. 1997. Practical intuition: How to harness the power of your instinct and make it work for you. New York, NY: Broadway Books.

Day, L. 2009. How to rule the world from your couch: Simon and Schuster.

Dörfler, V. \& Ackermann, F. 2012. Understanding intuition: The case for two forms of intuition. Management Learning, 43(5): 545-564.

Dörfler, V. \& Stierand, M. 2017. The underpinnings of intuition. In J. Liebowitz \& J. Paliszkiewicz \& J. Gołuchowski (Eds.), Intuition, trust, and analytics: 3-20. Boca Raton, FL: Taylor \& Francis. 
Dörfler, V. \& Stierand, M. 2018. Understanding indwelling through studying intuitions of nobel laureates and top chefs, AoM 2018: 78th Annual Meeting of the Academy of Management, Chicago, IL.

Duggan, W. 2013. Strategic intuition: The creative spark in human achievement. New York, NY: Columbia University Press.

Epstein, S., Pacini, R., Denes-Raj, V., \& Heier, H. 1996. Individual differences in intuitiveexperiential and analytical-rational thinking styles. Journal of Personality and Social Psychology, 71(2): 390-405.

Ericsson, A. \& Pool, R. 2016. Peak: Secrets from the new science of expertise. New York, NY: Houghton Mifflin Harcourt.

Gummesson, E. 2003. All research is interpretive! Journal of Business \& Industrial Marketing, 18(6/7): 482-492.

Hayashi, A. M. 2001. When to trust your gut. Harvard Business Review, 79(2): 59-65.

Hodgkinson, G. P., Langan-Fox, J., \& Sadler-Smith, E. 2008. Intuition: A fundamental bridging construct in the behavioural sciences. British Journal of Psychology, 99(1): $1-27$.

Hogarth, R. M. 2001. Educating intuition. Chicago, IL: University of Chicago Press.

Kahneman, D., Slovic, P., \& Tversky, A. 1982. Judgment under uncertainty: Heuristics and biases. New York, NY: Cambridge University Press.

Kahneman, D. \& Frederick, S. 2002. Representativeness revisited: Attribute substitution in intuitive judgment. In T. Gilovich \& D. Griffin \& D. Kahneman (Eds.), Heuristics and biases: The psychology of intuitive judgment: 49-81. Cambridge, UK: Cambridge University Press.

Kahneman, D. 2003. A perspective on judgment and choice: Mapping bounded rationality. American Psychologist, 58(9): 697-720. 
Kahneman, D. \& Klein, G. 2009. Conditions for intuitive expertise: A failure to disagree. American Psychologist, 64(6): 515-526.

Kahneman, D. 2011. Thinking, fast and slow. London, UK: Penguin Books.

Keren, G. 1987. Facing uncertainty in the game of bridge: A calibration study. Organizational Behavior and Human Decision Processes, 39(1): 98-114.

Kickul, J. R. \& Gundry, L. K. 2011. Entrepreneurial intuition. In M. Sinclair (Ed.), Handbook of intuition research: 88-96. Cheltenham, UK: Edward Elgar.

Klein, G. 2015. A naturalistic decision making perspective on studying intuitive decision making. Journal of Applied Research in Memory and Cognition, 4(3): 164-168.

Mielonen, S., Keinänen, M., Raami, A., \& Rouhiainen, L. 2009. Intuitive knowledge processes among design students, professional designers and expert intuitive practitioners, Communicating (by) Design 2009, Bruxelles, Belgium.

Neisser, U. 1963. The multiplicity of thought. British Journal of Psychology, 54(1): 1-14.

Prietula, M. J. \& Simon, H. A. 1989. The experts in your midst. Harvard Business Review, 67(1): 120-124.

Sadler-Smith, E. 2008. Inside intuition. London, UK: Routledge.

Salas, E., Rosen, M. A., \& DiazGranados, D. 2010. Expertise-based intuition and decision making in organizations. Journal of Management, 36(4): 941-973.

Schoemaker, P. J. H. \& Russo, J. E. 1993. Pyramid of decision approaches. California Management Review, 36(1): 9-31.

Schrödinger, E. 1958. Mind and matter. In E. Schrödinger (Ed.), What is life? With mind and matter and autobiographical sketches: 91-164. Cambridge: Cambridge University Press.

Simon, H. A. 1947. Administrative behavior: A study of decision-making processes in administrative organization ( $1^{\text {st }}$ ed.). New York, NY: Macmillan. 
Simon, H. A. 1983. Reason in human affairs. Stanford, CA: Stanford University Press.

Simon, H. A. 1987. Making management decisions: The role of intuition and emotion. Academy of Management Executive, 1(1): 57-64.

Sinclair, M., Ashkanasy, N. M., Chattopadhyay, P., \& Boyle, M. V. 2002. Determinants of intuitive decision making in management: The moderating role of affect. In N. M. Ashkanasy \& W. J. Zerbe \& C. E. J. Härtel (Eds.), Managing emotions in the workplace. New York, NY: M.E. Sharpe.

Sinclair, M. \& Ashkanasy, N. M. 2005. Intuition: Myth or a decision-making tool? Management Learning, 36(3): 353-370.

Sinclair, M. 2010. Misconceptions about intuition. Psychological Inquiry: An International Journal for the Advancement of Psychological Theory, 21(4): 378 - 386.

Stanovich, K. E. \& West, R. F. 1998. Individual differences in rational thought. Journal of Experimental Psychology: General, 127(2): 161-188.

Tantia, J. F. 2011. Viva las vagus! The innervation of embodied clinical intuition. The USA Body Psychotherapy Journal Editorial, 10(1): 29-37.

Tantia, J. F. 2014. Is intuition embodied? A phenomenological study of clinical intuition in somatic psychotherapy practice. Body, Movement and Dance in Psychotherapy, 9(4): 211-223.

Trailer, J. W. \& Morgan, J. F. 2004. Making "good" decisions: What intuitive physics reveals about the failure of intuition. Journal of American Academy of Business, Cambridge, 4(1-2): 42-48.

Tversky, A. \& Kahneman, D. 1974. Judgment under uncertainty: Heuristics and biases, Science, Vol. 185: 1124-1131.

Tversky, A. \& Kahneman, D. 1983. Extensional versus intuitive reasoning: The conjunction fallacy in probability judgment. Psychological Review, 90(4): 293-315. 
Weick, K. E. 1979. The social psychology of organizing (2 ${ }^{\text {nd }}$ ed.). New York, NY: McGrawHill.

Weick, K. E. 1995. Sensemaking in organizations. Thousand Oaks, CA: Sage Publications. 